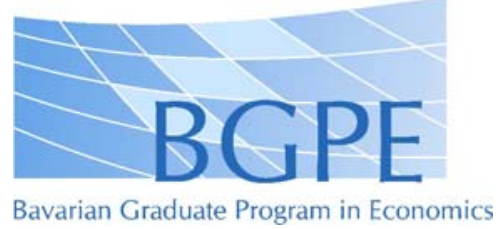

BGPE Discussion Paper

No. 57

\title{
The design of political institutions: Electoral competition and the choice of ballot access restrictions in the United States
}

\author{
Marcus Drometer \\ Johannes Rincke
}

September 2008

ISSN 1863-5733

Editor: Prof. Regina T. Riphahn, Ph.D.

Friedrich-Alexander-University Erlangen-Nuremberg

(c) Marcus Drometer, Johannes Rincke 


\title{
The design of political institutions: Electoral competition and the choice of ballot access restrictions in the United States
}

\author{
Marcus Drometer* \\ Department of Economics, \\ University of Munich
}

\author{
Johannes Rincke** \\ Department of Economics, \\ University of Munich, and CESifo
}

September 2008

\begin{abstract}
Recent contributions to the political economics literature (Trebbi et al. 2007; Aghion et al. 2004) have challenged the view that political institutions are exogenous to the behavior of agents in the political arena. We explicitly address the potential endogeneity of institutions by examining the link between the degree of electoral competition and the design of ballot access restrictions in the United States. Exploiting exogenous variation in electoral competition at the state level induced by the federal Voting Rights Act of 1965, our main finding is that restrictions to the entry of minor party and independent candidates have been systematically adjusted to changing degrees of electoral competition.
\end{abstract}

Keywords: Political institutions, electoral competition, ballot access

JEL Classification: D72, D78

\footnotetext{
${ }^{*}$ Contact: Seminar for Economic Policy, Department of Economics, University of Munich, Akademiestr. 1/II, D-80799 Munich. Phone: +49 89 2180-2249, fax: +49 89 2180-6296, email: marcus.drometer@lrz.uni-muenchen.de.

${ }^{* *}$ Corresponding author. Contact: Seminar for Economic Policy, Department of Economics, University of Munich, Akademiestr. 1/II, D-80799 Munich. Phone: +49 89 2180-6753, fax: +49 89 2180-6296, email: johannes.rincke@lrz.uni-muenchen.de.
} 


\section{Introduction}

Most of the literature on constitutional choice and electoral rules has treated political institutions as exogenous constraints on policymakers. For instance, an influential recent line of thinking comprising, among others, Rodrik (1999) and Persson and Tabellini (2003) has discussed institutions as predetermined factors driving key economic outcomes. Only very recently a positive approach to the choice of political institutions has been suggested. It seeks to explain why different societies have different political institutions, and tries to figure out the determinants of institutional change. The positive approach starts from the simple but intriguing idea that, after all, political institutions are chosen by individuals and are not randomly assigned to countries and societies. Alesina and Glaeser (2004), for instance, deal with the strategic choice of electoral rules, focussing on the implications of alternative constitutional choices on the welfare state. Acemoglu and Robinson (2000) explain the extension of voting rights in western societies as the outcome of strategic choices of political elites to prevent social unrest. The tradeoff between delegation of power and ex-post control of politicians is analyzed in Aghion et al. (2004). Finally, Trebbi et al. (2007) report evidence that the choice of electoral rules in U.S. cities varies with the share of minorities in a way that effectively limits minority representation.

Despite the fact that a re-design of political institutions by self-interested political elites has potentially far-reaching consequences, there is little empirical evidence for endogenous institutional change. This paper contributes to the literature by investigating the endogeneity of a particular institution, namely ballot access rules for third-party and independent candidates in the United States. While in the U.S. major party candidates are being determined by primary elections or caucuses, minor parties and independent candidates commonly need to file a petition signed by a certain number of eligible voters. ${ }^{1}$ Recent empirical work shows that these requirements have

\footnotetext{
${ }^{1}$ Despite the fact that a majoritarian voting system as in the U.S. promotes the existence of two dominating political parties (Duverger, 1964), third-party as well as independent candidates frequently appear on ballots in state as well as federal elections. During the period considered here (1946-1976), 46\% of the gubernatorial races saw three or more candidates, while $50 \%$ had two candidates and $4 \%$ were uncontested. In U.S. House elections, the corresponding numbers were $28 \%$
} 
strong deterrent effects on third party and independent candidates: Ansolabehere and Gerber (1996) find that higher filing fees increase the frequency of uncontested races and decrease the frequency of retirements in congressional elections. In the same vein, Stratmann (2005) demonstrates that filing fees deter third party candidates in state level Lower House elections. Finally, Drometer and Rincke (2008) exploit the Supreme Court decision of 1968 to strike down Ohio's highly restrictive ballot access law as a natural experiment and find that the number of third party and independent candidates increased considerably. Hence, choosing ballot access rules as an example of a (potentially) endogenous institution is justified by the fact that a tightening of the underlying state laws will have an immediate impact on the effective level of electoral competition. As recently discussed by Besley et al. (2006), this may in turn have strong effects on the quality of governance and thereby economic performance.

As a first step of the analysis, we set up a simple theoretical model which illustrates the optimal choice of barriers to entry to the political arena from the point of view of a self-interested incumbent political party. The incumbent party is assumed to adjust the barrier to changes in exogenous conditions affecting the effective degree of electoral competition. The model thus treats the effective degree of competition as an endogenous variable which depends on exogenous conditions as well as the barrier set by the incumbent party. In a second step, we investigate whether the design of ballot access requirements in U.S. states is systematically related to the degree of competition in gubernatorial elections. This exercise is complicated by the fact that the observable degree of electoral competition already reflects the deterrent effect of existing ballot access requirements on potential third party and independent candidates: in states with few such candidates, the major parties will face low competition even without any ballot access requirement, while in states with many active political parties a similar level of effective competition might be the outcome of more restrictive requirements. Naive estimates relating the stringency of ballot access rules to observed levels of electoral competition are therefore likely to be misleading.

Our strategy to solve the endogeneity problem exploits the federal Voting Rights Act (three or more candidates), 59\% (two candidates) and 13\% (uncontested). 
(VRA) of 1965 as a natural experiment. Before the mid-1960s, politics in the southern states $^{2}$ was characterized by a quasi-monopoly of the Democratic Party and the practical disenfranchisement of most black voters. The VRA effectively removed barriers to the political participation of blacks such as poll taxes and literacy tests and led to a rapid and significant increase in registration rates among black voters: taking all southern states together, registration among blacks jumped from 35.5\% in 1964 to $64.8 \%$ in $1969 .^{3}$ The increased political participation of black voters had a substantial effect on the political supply side, i.e. on political parties and potential candidates for public office: while in all non-southern states the average number of candidates in gubernatorial elections showed a moderate change from 2.6 in the years immediately before the VRA (1958-1964) to 2.9 in the period 1966-1972, the respective figure considerably increased from 2.1 to 2.8 in the southern states.

Our strategy to exploit the variation in electoral competition induced by the VRA proceeds in two steps. In the first step, we substantiate the claim that the VRA is a source of exogenous variation in the number of candidates in gubernatorial elections, and that this variation is strong enough to solve our identification problem. In particular, we estimate the treatment effect of the VRA on the number of candidates in states with a substantial black minority by a series of difference-in-difference estimations. The main finding across various specifications and robustness checks is that the federal intervention of 1965 indeed had a significant impact on the number of candidates. We check this result against a number of alternative explanations for the increase in the number of candidates in southern states. In particular, we show that the significant increase in electoral competition cannot be explained by the gradual catch up of the South in terms of educational attainment, income, and urbanization.

Our main result is established in the second step of the empirical analysis, where we derive estimates of the impact of electoral competition on the stringency of ballot access laws in terms of signature requirements for third-party and independent candidates. To overcome the endogeneity problem, we construct an instrumental variable

\footnotetext{
${ }^{2}$ We use the definition of the Census Bureau and treat as southern states Alabama, Arkansas, Florida, Georgia, Louisiana, Mississippi, North Carolina, South Carolina, Texas, and Virginia.

${ }^{3}$ See Statistical Abstract of the United States (1970, p. 369).
} 
for the number of candidates which captures the variation in electoral competition induced by the VRA. We construct the instrument in such a way that the differencein-difference estimations derived in the first step of the analysis can be interpreted as first stage regressions of our instrumental variable estimations. Based on data for the period 1946-1976, our findings point to a strong impact of electoral competition on the stringency of the states' ballot access laws. On average, an additional candidate on the ballot has triggered an increase in petition requirements in the order of 7,500 to 10,000 signatures. Again, we perform several robustness checks to validate our findings. Taken together, the empirical analysis suggests that the states have systematically tightened their ballot access laws in reaction to increased levels of electoral competition. Hence, ballot access regulations provide an example of endogenous political institutions.

The paper is organized as follows. The theoretical model illustrating the behavior of an incumbent party in setting barriers to entry is presented in Section 2. Section 3 sheds light on the historical background of our empirical analysis in general and the VRA in particular. The empirical approach and the data are discussed in Section 4. Section 5 presents our results, and Section 6 concludes.

\section{Setting optimal barriers to entry}

This section provides a simple theoretical framework for the following empirical discussion. In particular, the model highlights the role of incumbent political parties which choose optimal barriers to prevent the entry of political competitors.

Consider an economy with political parties competing for power. We focus on the choice of the 'rules of the game' by an incumbent political party, in particular, the setting of a barrier to entry, $B$. The barrier affects the degree of effective competition, described by the well-behaved function $C$ according to

$$
C=C(\tilde{C}, B)
$$


where $\tilde{C}$ summarizes exogenous conditions that influence $C$. We call $\tilde{C}$ latent competition. Using subscripts to indicate partial derivatives, let $C_{\tilde{C}}>0$ and $C_{B}<0$. In addition, we assume $C_{B B}>0$, meaning that increasing the barrier reduces its marginal impact on $C$, and $C_{B \tilde{C}}<0$, saying that a given increase in $B$ is more effective the more candidates are seeking access to elections.

To capture the idea that incumbent parties usually dislike a situation with strong electoral competition, we define a benefit function $V(C)$ with $V_{C}<0$. However, setting higher barriers to entry comes at a cost, captured by a cost function $K(B)$ with $K_{B}>0$ and $K_{B B}>0$. In practical terms, one may think of negative effects on the incumbent party's general reputation, or of higher political effort needed to implement a more restrictive rule. ${ }^{4}$ In total, the incumbent party maximizes the difference between the benefits and costs of setting $B$,

$$
V-K=V(C(\tilde{C}, B))-K(B)
$$

From the first-order condition, $V_{C} C_{B}-K_{B}=0$, we obtain

$$
\frac{d B}{d \tilde{C}}=\frac{V_{C} C_{B \tilde{C}}+V_{C C} C_{\tilde{C}} C_{B}}{K_{B B}-V_{C} C_{B B}-V_{C C} C_{B} C_{B}}
$$

As long as the second-order condition holds (i.e. the denominator is positive), the sign of $\frac{d B}{d \tilde{C}}$ is positive unless $V_{C C}$ is strongly positive. In particular, $\frac{d B}{d \tilde{C}}>0$ will hold if the reduction in utility when competition increases is constant $\left(V_{C C}=0\right)$. Hence, for a wide range of benefit functions, our model predicts a re-design of rules defining barriers to entry in a way that an increase in latent competition triggers more restrictive regulations.

In the empirical part of the paper we test for an endogenous adjustment of $B$, taking the ballot access restrictions of the U.S. states as an example. This is complicated by the fact that the exogenous conditions driving the observed degree of electoral competition are difficult (if not impossible) to capture. Hence, we lack a convincing

\footnotetext{
${ }^{4}$ Ballot access laws have been challenged in court several times. In 1968, for instance, the Supreme Court declared Ohio's ballot access law unconstitutional, and the state had to reduce the requirements for third-party and independent candidates considerably.
} 
empirical counterpart of $\tilde{C}$. Therefore, our approach to estimate the effect of electoral competition on the stringency of ballot access restrictions rests on the idea to use a readily observable measure for effective competition (such as the number of candidates appearing on the ballot) as the key explanatory variable and to account for the endogeneity of this measure (i.e. the fact that $\tilde{C}$ itself depends on $B$ ) by instrumental variables. Intuitively, the instruments serve as a substitute for latent competition as the unobservable explanatory variable of interest. Before turning to the empirical part, however, we briefly review some key historical facts our identification approach is based upon.

\section{Historical Background}

Our identification strategy builds on exogenous variation in state-level electoral competition that was induced by the abolishment of voting rights regulations in the southern states in 1965. In the following, we provide a summary of the relevant historical facts. ${ }^{5}$

Since the 1880s the Democratic Party had established a political quasi-monopoly in the U.S. South with its representatives often remaining uncontested in elections. This position was partly built on the effective disenfranchisement of black voters. Among others, black citizens were refused their political rights by all-white Democratic primaries and so-called 'Grandfather Clauses' which limited the right to vote to those individuals whose grandparents had it before the Civil War. Moreover, political participation of blacks was obstructed by poll taxes and literacy tests. Though poll taxes were comparatively low, they discouraged many poor blacks from casting their vote. Literacy tests were used in an arbitrary manner to discourage black voters from registering. As a consequence, only a small fraction of black citizens registered for voting. In 1960 the average registration rate among blacks in the South was only 29.1\%, in contrast to $61.1 \%$ among white citizens. In some states, the asymmetry in registration

\footnotetext{
${ }^{5}$ For more details, see, e.g., Lawson (1976) and Grofman et al. (1992). Besley et al. (2006) provide a related description of the historical background.
} 
rates was even more pronounced. In Mississippi, for example, in 1960 only $5.2 \%$ of the blacks, but $63.9 \%$ of the whites were registered. ${ }^{6}$

The attempts of the black citizens in the southern states to change their lot were largely unsuccessful for a long period of time. Only after the landmark decision Brown v. Board of Education by the Supreme Court in 1954, which struck down racial segregation in public schools, the black reform movements started to gain momentum. The Civil Rights Movement culminated ten years later in the 1963 'March on Washington' and Martin Luther King's 'I have a dream' speech. As a response to the growing discomfort among black citizens, the Johnson administration decided to support the reform movement by federal legislation, in particular by the Civil Rights Act (CRA) in 1964 and the Voting Rights Act in 1965. But whereas the black reform movement developed gradually, the cornerstones of the federal civil rights legislation were enacted in a quick succession of events. In particular, it seems that the actions taken by the Johnson administration were largely driven by unforeseen media coverage of a number of singular events.

One of the unforseen events that triggered legislative activity of the Johnson administration was the murder of three civil rights activists in Mississippi on June 21, 1964. The subsequent public outrage made the Republicans join the Northern Democrats against the Southern Democrats to pass the CRA which president Johnson immediately signed into law on July 2, 1964. Among other things, the CRA made voting restrictions in federal elections illegal, but the existing restrictions at the state level remained in place. It does not seem that the Johnson administration had any intention to amend the CRA after the 1964 elections. ${ }^{7}$ Yet, further events, especially the attack by state troopers on peaceful demonstrators walking from Selma, Alabama, to the state capital Montgomery on March 7, 1965, received tremendous media attention and made president Johnson send a proposal for a strict enforcement of voting rights to Congress on March 17, 1965. The Senate and the House passed the bill at the beginning of August. On August 6, 1965, president Johnson signed the VRA into law.

\footnotetext{
${ }^{6}$ For more details on voter registration in the South between 1960 and 1970, see Statistical Abstract of the United States (1971, p. 365).

${ }^{7}$ See also Besley et al. (2006).
} 
The VRA finally suspended the use of poll taxes and literacy tests by the states. Moreover, it authorized federal supervision of voter registration in states, or counties, where such restrictions had been used in the past and where less than $50 \%$ of the voting age population was registered. Accordingly, the implementation of the prescriptions of the VRA was very strict and highly effective. This stands in contrast to all previous attempts of federal legislators to abolish the political disenfranchisement of blacks in the South. Until 1965 these efforts were largely unsuccessful as the southern Democrats persistently obstructed any federal initiative addressing the discrimination of blacks. ${ }^{8}$ Due to the strict enforcement of the VRA, the registration of black voters increased substantially, and the political landscape of the South was quickly and fundamentally transformed. As a consequence, the quasi-monopoly of the Democratic Party in the southern states came to an end. Already in 1966, the first Republican governors in the South in the 20th century were elected in Arkansas (W. Rockefeller) and Florida (C.R. Kirk). Until the mid-seventies, Republicans became governors also in North Carolina (J.E. Holshouser, 1972), South Carolina (J.B. Edwards, 1974), and Virginia (L. Holton, 1969).

\section{Empirical approach and data}

In this section we discuss our identification strategy regarding the effect of electoral competition on the stringency of ballot access restrictions. We also briefly review our data and present summary statistics.

\subsection{Estimation approach}

Our analysis aims at providing evidence of the effect of electoral competition on the design of ballot access laws in the U.S. The identification of this effect is complicated

\footnotetext{
${ }^{8}$ For a detailed account of the long and unsuccessful struggle against voting rights restrictions in the South see Lawson (1976).
} 
by the apparent endogeneity of variables that measure the effective degree of electoral competition. To overcome this problem, our estimation strategy exploits variation in electoral competition which was triggered by the VRA and, therefore, is exogenous to the states' ballot access regulations. In particular, we make use of the fact that the VRA considerably increased the overall level of political participation in states with a relatively high black population share, whereas it left states with relatively few blacks more or less unaffected.

Before explaining our identification strategy in detail, let us briefly discuss the structural equation of interest which reads

$$
B_{i t}=\alpha C_{i t}+X_{i t} \beta+\theta_{i}+\tau_{t}+e_{i t},
$$

where $B_{i t}$ measures the stringency of ballot access restrictions in state $i$ in year $t, C_{i t}$ is the degree of electoral competition, and $X_{i t}$ denotes a vector of state characteristics that potentially affect the stringency of ballot access requirements. Unobserved state effects and period-specific effects are captured by $\theta_{i}$ and $\tau_{t}$, while $e_{i t}$ denotes a residual.

We use the number of petitions that minor-party and independent candidates need to submit in order to be placed on the gubernatorial ballot as a measure for $B$. As mentioned before, these signature requirements are often substantial and constitute a significant barrier to entry for third party and independent candidates. In general, the variation in the petition requirement is substantial, both across states and over time. ${ }^{9}$ Note further that other restrictions like filing fees and tight deadlines during the application process seem to be less important in practice: filing fees for gubernatorial candidates are of negligible size in the majority of states, and where they are not, several Supreme Court rulings require that alternative means for gaining ballot access have to be specified. Similarly, due to a number of court decisions, the leeway to adjust deadlines that have to be met during the application process (like for filing petitions) is very limited in practice.

With regard to $C$, we use either the total number of candidates appearing on the

\footnotetext{
${ }^{9}$ See Bott (1990) for details on the states' ballot access laws and the following subsection for descriptive statistics on signature requirements.
} 
ballot or the number of third-party and independent candidates. At first glance, the latter measure seems to be the better choice since it is more closely related to the stringency of ballot access restrictions for minor-party and independent candidates. Recall, however, that uncontested gubernatorial races were quite frequent prior to 1965 in the southern states. The significant increase in electoral competition faced by the southern Democrats in the aftermath of the VRA was to a considerable extent due to candidates of the Republican Party regularly appearing on gubernatorial ballots. This in turn might have triggered adjustments of ballot access requirements in general, and in particular for minor-party and independent candidates. We therefore use the total number of candidates as a measure for electoral competition in most estimations and report results based on the number of third party and independent candidates as a robustness check.

The prime role of the control variables is to account for a possible effect of key economic and social-demographic indicators on signature requirements. For instance, more populous states might choose higher signature requirements. Similarly, it might be that the leading parties are more likely to face significant competition in wealthier and more urbanized states. Therefore, we allow for an independent effect of total state population, per-capita income, educational attainment as well as urbanization.

The coefficient of interest in our structural equation is $\alpha$. It captures the extent to which states re-design their ballot access requirements in response to changes in the degree of electoral competition. We expect a positive sign of $\alpha$, indicating that states tend to make access to the ballot more difficult for third-party and independent candidates if major parties face more competition. However, recall from the discussion of the theoretical model that, because the effective degree of electoral competition already reflects the impact of $B$, estimating $\alpha$ from a naive regression is uninformative. Technically, the dependence of $C$ on $B$ induces correlation between our main explanatory variable and the residual, which renders parameter estimates from simple OLS regressions inconsistent. Our approach to solve the endogeneity problem is to identify a source of exogenous variation in electoral competition at the state level and to exploit this variation in order to derive instrumental variables for $C$. If the exogenous 
variation captured by the instruments is sufficiently strong, a two-stage least squares (2SLS) regression will identify the effect of interest. Intuitively, the instrumental variables are used as a substitute for $\tilde{C}$, the unobservable exogenous variable of interest in the theoretical model.

Our choice of instruments exploits the extraordinary impact of the VRA on the political participation of blacks in the South. To the extent to which the resulting increase in black voter participation triggered an increase in electoral competition in those states which were affected by the federal legislative initiative, the intervention has the potential to provide us with variation in the number of candidates that is arguably exogenous to the states' ballot access requirements. A straightforward way to investigate the differential impact of the abolishment of impediments to black voter participation is to estimate the impact of the VRA on the number of gubernatorial candidates by means of a difference-in-difference approach. In its simplest form, a corresponding estimation equation looks like

$$
C_{i t}=\gamma \text { Black } \times V R A_{i t}+\tilde{X}_{i t} \delta+\tilde{\theta}_{i}+\tilde{\tau}_{t}+u_{i t}
$$

where $C_{i t}$ again represents the degree of electoral competition, i.e. either the total number of candidates or just the number of minor-party and independent candidates. Black $\times V R A$ is the interaction between an indicator for states which were affected by the federal intervention, Black, and a second indicator, $V R A$, which takes value zero for all years prior to 1966 and value one for the years starting from 1966 (the post-shock periods). $\tilde{X}_{i t}$ is a vector of control variables, where the tilde indicates that the vector is allowed to differ from the corresponding vector $X_{i t}$ in Equation (4). As in our main estimation, we also include state effects, $\tilde{\theta}_{i}$, and period effects common to all states, $\tilde{\tau}_{t}$.

The purpose of the difference-in-difference estimations is to check whether (and to what extent) the VRA increased electoral competition in the subset of affected states. We will therefore focus on the coefficient of the interaction term, $\gamma$, which captures the differential impact of the federal intervention. With respect to the definition of Black, recall that most of the southern states were immediately affected by the VRA 
because they were forced to abolish impediments to black voter participation like poll taxes and literacy tests. ${ }^{10}$ Note, however, that even in states that did use neither poll taxes nor literacy tests at the time of the VRA, the political participation of blacks rose considerably. Florida, for instance, had abolished poll taxes already in 1937 and did not use formal literacy tests. Notwithstanding, the registration rate of blacks increased from $39.4 \%$ in 1960 to $55.3 \%$ in 1970, while the registration rate among whites decreased from $69.3 \%$ to $65.5 \% .^{11}$ In general, the available data on registration and voting behavior between 1960 and 1970 suggest that the VRA had substantial effects on the political participation of blacks in all states. To account for this, we use the size of the black minority in order to assign states to treatment and control group for the difference-in-difference estimations. In particular, we define all states with more than $10 \%$ black population in 1960 as Black. ${ }^{12}$

Equation (5) suggests a straightforward way to derive instruments for the number of candidates in the main structural equation (4). The difference-in-difference estimation identifies the effect of increased voter participation induced by the VRA on electoral competition. If the states in the treatment group (those strongly affected by the federal intervention) experienced a significant increase in electoral competition, we should find positive and statistically significant estimates for $\gamma$, indicating a significant partial correlation between the interaction term and the degree of electoral competition. Thus, if $\gamma$ is found to be statistically different from zero, our difference-in-difference estimation procedure would suggest to use Black $\times V R A$ as an instrument for the endogenous electoral competition measure $C$ in our main structural equation.

Of course, to obtain valid instruments for the degree of electoral competition, we do not only need to establish that the instruments are correlated with the endogenous explanatory variable, but also that the instruments are truly exogenous to the stringency

\footnotetext{
${ }^{10}$ These were Alabama, Arizona, Georgia, Louisiana, Mississippi, North Carolina, South Carolina, Virginia and Texas.

${ }^{11}$ Statistical Abstract of the United States (1971, p. 365).

${ }^{12}$ All our results are robust to moderate changes of this threshold. In particular, we checked whether the inclusion of states which were close to the $10 \%$-threshold in 1960 into the treatment group (such as Kentucky with 7.1\% blacks, Pennsylvania (7.5\%), Missouri (9.0\%), Michigan (9.2\%), and Illinois $(10.3 \%)$ ) affects the results of the difference-in-difference as well as the 2SLS estimations.
} 
of the states' ballot access provisions. As we have argued in the previous section, both the CRA and the VRA were imposed on the southern states by the federal government. Moreover, we have pointed out that the enactment and implementation of both acts was an unprecedented event. In particular, it seems to be highly unlikely that state policymakers did anticipate the federal intervention they experienced in the course of the 1964/65 events. Note furthermore that neither the CRA nor the VRA did address the use of ballot access requirements by the states. It therefore seems to be justified to treat the federal legislative intervention of 1964/65 as exogenous to the design of ballot access rules. Moreover, we account for the fact that ballot access laws in some states specify an absolute number of signatures, while in others the requirement is given as a percentage of registered voters or votes cast in the preceding general election. In states with a relative definition, an increase in turnout (or the number of registered voters, depending on the specification of the corresponding state law) will automatically increase the number of petitions required to get access to the ballot in the next election. To ensure that our instrument can still be validly excluded from the main estimation equation, we have to account for the direct effect of participation by appropriate explanatory variables. Therefore, we construct two indicator variables, one for states with a relative definition of the signature requirement and one for states with an absolute definition. In our main estimation, we include the interactions of both indicators with the number of votes cast in the preceding election as additional control variables. Finally, we also include the indicator for states with a relative definition.

We complete the description of the empirical approach by discussing the choice of the control variables in the difference-in-difference regressions which are essentially the same as in the 2SLS estimations. In particular, we allow for an independent effect of per capita income, educational attainment and urbanization in order to account for the possibility that an increase in the number of candidates for governor in southern states might be due to the economic catching-up of the South. For example, higher levels of educational attainment might induce more citizens to participate in politics, thereby increasing the number of candidates. Furthermore, we account for the possibility that more populous states may see more candidates by including state population as an 
additional regressor.

\subsection{Data}

The cross-sectional dimension of our sample is given by the population of contiguous U.S. states. Regarding the time dimension, we make use of the gubernatorial election years between 1946 and 1976. The group of states which are assumed to having experienced a significant shock in the overall level of political participation in 1964/65 is defined based on the population share of blacks in 1960, requiring a share of at least 10 percent. This definition gives a set of 14 states for which the indicator Black is set to one, consisting of Alabama, Arkansas, Delaware, Florida, Georgia, Illinois, Louisiana, Maryland, Mississippi, North Carolina, South Carolina, Tennessee, Texas and Virginia. Note that this list includes all southern states according to the definition of the Census Bureau.

Our measures of electoral competition are based on gubernatorial election outcomes as reported in ICPSR (1994). The data provide information on each individual candidate. Yet, especially for the early years, the assignment of party codes to individual candidates is imprecise in some cases. This is due to the fact that for some states the sources ICPSR (1994) is based on did not properly distinguish between minor-party candidates and write-in candidates. In all such cases, we checked and corrected the party codes by comparing the respective records in the ICPSR data to the information on individual candidates in various editions of the handbook on U.S. election statistics by R.M. Scammon.

The main source for the preparation of data on signature requirements for third-party and independent candidates in gubernatorial elections were hard copies of the states' statutes for the whole period 1946-1976. In general, we define our measure of the stringency of ballot access restrictions for minor-party and independent candidates as the number of signatures needed on a petition. In states where the election law specified requirements that differed between minor party and independent candidates, 
we chose the lower number. In case the number of petition was defined as a percentage of either the number of votes cast in the last general election or the number of registered voters, we calculated the implied absolute number of signatures using data on the number of votes cast from ICPSR (1994) and data on the number of registered voters from the Statistical Abstract of the United States (various editions). When the number of registered voters was unavailable for the respective election, we linearly interpolated using the numbers from the next available years. In a second step, we cross-checked the numbers obtained from the states' statutes, using the information on petition requirements in presidential elections in Winger (2006), Appendix F (in most states, ballot access requirements for presidential and gubernatorial elections are the same) as well as Bott (1990). In some cases, we were not able to figure out the precise signature requirement for gubernatorial elections, mostly because the respective state laws specified alternative ways to get on the ballot rendering it difficult to determine the exact signature requirement. ${ }^{13}$ Note in particular that we had to exclude the following states from the analysis altogether: New York, Vermont, Ohio, Washington, New Jersey, and Wisconsin. For New Jersey, Washington and Wisconsin we had difficulties in deriving a consistent measure for the signature requirement because the respective state laws allow for various alternative means to get ballot access. In New York and Vermont, individual candidates in gubernatorial elections often represent multiple political parties. Our measure for electoral competition for these states is thus not comparable to the remaining states. Finally, Ohio's ballot access law was struck down by the Supreme Court in 1968 as being overly restrictive. Since our approach aims at identifying endogenous adjustments of ballot access rules, we do not want to make use of variation which is known to be driven by exogenous forces.

The data on state characteristics that serve as control variables come from the Bureau of the Census. They include total state population, per capita income (deflated to 1960 dollars), educational attainment (percentage of total population 25 years and over with a high school diploma or a higher degree), and urbanization (percentage of

\footnotetext{
${ }^{13}$ For instance, some state laws offer minor parties the opportunity to hold a party convention with a certain minimum number of attendees that can nominate a candidate whose name will then appear on the ballot.
} 
Table 1: Petition requirements for minor-party and independent candidates, 1946-1976

\begin{tabular}{lccccc}
\hline Period & Nob & Mean & Std. Dev. & Min & Max \\
\hline $1946-1976$ & 410 & 8476 & 16034 & 0 & 103208 \\
$1946-1956$ & 170 & 5477 & 11388 & 0 & 57306 \\
$1958-1966$ & 135 & 9254 & 16987 & 0 & 74223 \\
$1968-1976$ & 105 & 12329 & 19951 & 0 & 103208 \\
\hline
\end{tabular}

Samples comprise states in gubernatorial election years in the respective period. Sources: Revised State Codes (various years) and Winger (2006).

Table 2: Summary statistics

\begin{tabular}{|c|c|c|c|c|}
\hline Variable & Mean & Std. Dev. & Min & Max \\
\hline Total \# of candidates & 2.72 & 1.20 & 1 & 9 \\
\hline \# of minor-party \& independent cand's & 0.749 & 1.15 & 0 & 7 \\
\hline 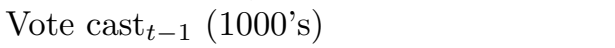 & 905 & 1067 & 40.7 & 6510 \\
\hline Signature requirement relative & 0.368 & 0.483 & 0 & 1 \\
\hline Black & 0.298 & 0.458 & 0 & 1 \\
\hline VRA & 0.326 & 0.469 & 0 & 1 \\
\hline Black $\times$ VRA & 0.110 & 0.313 & 0 & 1 \\
\hline Total population (1000's) & 3111 & 3215 & 143 & 21173 \\
\hline Per capita income (in dollars of 1960) & 6228 & 1767 & 2701 & 11360 \\
\hline Educational attainment & 42.7 & 11.0 & 18.9 & 74.9 \\
\hline
\end{tabular}

Sample comprises states in gubernatorial election years, 1946-1976 (Nob=410). Sources: ICPSR (1994) and Statistical Abstract of the United States (various years). Total \# of candidates, \# of minor-party and independent candidates and vote cast for general elections only. 'Black' is an indicator for states with a population share of blacks higher than $10 \%$ in 1960. VRA is an indicator for post-VRA periods, i.e. 1966-1976. Educational attainment is share of total population 25 years and over with a high school diploma or a higher degree. Urbanization is share of urban population as defined by the Census Bureau.

urban population as defined by the Census Bureau).

Table 1 entails summary statistics for petition requirements as specified in the respective state election laws. We note that there is substantial variation in signature requirements both across states and across time. While in the period 1946-1956 the average number of signatures required to put a non-major party candidate on a gubernatorial ballot was about 5,500, that number more than doubled to reach more than 12,000 in the period 1968-1976. In addition, the standard variation increased considerably.

Table 2 shows summary statistics for the explanatory variables in our main structural equation. Our key explanatory variables are shown in the first two rows. Note in particular that minor-party and independent candidates appear on gubernatorial ballots quite frequently. 
Table 3: Effect of VRA on electoral competition, difference-in-difference estimations

\begin{tabular}{|c|c|c|c|c|c|}
\hline \multicolumn{4}{|c|}{$\begin{array}{l}\text { Dependent variable: Number of candidates in gubernatorial elections, } \\
\text { all parties }\end{array}$} & \multicolumn{2}{|c|}{ minor parties } \\
\hline & (1) & $(2)$ & $(3)$ & (4) & (5) \\
\hline Black $\times$ VRA & $\begin{array}{l}0.591^{\star \star} \\
(0.235)\end{array}$ & $\begin{array}{l}0.583^{\star \star} \\
(0.219)\end{array}$ & $\begin{array}{l}0.597^{\star \star} \\
(0.241)\end{array}$ & $\begin{array}{l}0.518^{\star \star} \\
(0.216)\end{array}$ & $\begin{array}{l}0.538^{\star \star} \\
(0.233)\end{array}$ \\
\hline VRA & $\begin{array}{l}0.312^{\star \star} \\
(0.117)\end{array}$ & - & - & - & - \\
\hline Population & - & - & $\begin{array}{r}0.00007^{\star \star} \\
(0.00003)\end{array}$ & - & $\begin{array}{l}0.00006^{\star} \\
(0.00003)\end{array}$ \\
\hline Per-capita income & - & - & $\begin{array}{l}-0.0002 \\
(0.0002)\end{array}$ & - & $\begin{array}{l}-0.0002 \\
(0.0002)\end{array}$ \\
\hline Educational attainment & - & - & $\begin{array}{c}0.059 \\
(0.080)\end{array}$ & - & $\begin{array}{c}0.043 \\
(0.074)\end{array}$ \\
\hline Urbanization & - & - & $\begin{array}{c}0.014 \\
(0.016)\end{array}$ & - & $\begin{array}{c}0.011 \\
(0.016)\end{array}$ \\
\hline Year effects & no & yes & yes & yes & yes \\
\hline State effects & yes & yes & yes & yes & yes \\
\hline$R^{2}$ & 0.49 & 0.54 & 0.55 & 0.54 & 0.55 \\
\hline
\end{tabular}

Sample includes gubernatorial elections from 1946 to 1976 (429 observations), see text for details. Standard errors (robust to heteroscedasticity and serial correlation) in parentheses. 'Black' is an indicator for states with a black population share exceeding $10 \%$ in 1960. 'VRA' is an indicator for elections taking place after the VRA, i.e. 1966-1976. Significance levels: ${ }^{\star \star} 5 \%$; ${ }^{\star} 10 \%$.

\section{Results}

\subsection{The effect of the VRA on electoral competition}

Before we turn to our main results, we will first discuss the results of the differencein-difference estimations regarding the impact of the VRA on electoral competition. The first set of results is displayed in Table 3. Column (1) shows the treatment effect for a baseline specification that accounts only for state effects and the indicator for post-shock years, $V R A$, as additional explanatory variables. Relative to the states in the control group, the effect of the VRA on the number of candidates in the states with a significant black minority is estimated to be about 0.6. Column (2) depicts the results if we account for a full set of year effects instead of $V R A$. The coefficient of the treatment effect is virtually unchanged and still significant at the $5 \%$ level. To account for an independent effect of state characteristics which might be related to the number of candidates in gubernatorial elections, Column (3) reports a specification 
that includes total state population, per-capita income, educational attainment, and urbanization as additional explanatory variables. Among the control variables, only population proves to be significant. The coefficient indicates that if the population grows by 1 million, the number of candidates increases by 0.07 . More importantly, the estimated effect of the VRA on the number of candidates is unaffected by the inclusion of the additional control variables and still significant at the $5 \%$ level.

Further evidence for the effect of the VRA on electoral competition is provided in Columns (4) and (5). Here, we have defined the dependent variable as the number of minor-party and independent candidates as opposed to the total number of candidates in the previous regressions. As expected, switching to this narrower definition does not have any sweeping effect on our estimates. The somewhat smaller point estimates for the treatment effect just reflect that part of the increase in electoral competition in the southern states after the VRA was due to candidates of the Republican Party now regularly appearing on gubernatorial ballots. To summarize, Table 3 confirms a strong effect of the VRA on the number of candidates in gubernatorial elections.

\subsection{The effect of electoral competition on the design of ballot access}

Let us now turn to the impact of electoral competition on the stringency of the states' ballot access requirements, i.e. the number of signatures required for minor-party and independent candidates to be placed on the ballot in gubernatorial elections. As discussed in the previous section, we identify this competition effect by means of 2SLS estimations accounting for unobserved heterogeneity at the state level. Drawing on the strong partial correlation between the interaction term Black $\times V R A$ and the number of candidates identified by the series of difference-in-difference estimations shown above, we use Black $\times V R A$ as an instrument for electoral competition.

As before, Table 4 reports estimated coefficients along with standard errors which are robust to both heteroscedasticity and serial correlation. While we use the same set of states as in the difference-in-difference estimations shown above, we now have 
Table 4: Effect of electoral competition on stringency of signature requirements, IV estimations

Dep. variable: Signature requirement for minor-party and independent cand.'s in gub. elections

Total number of candidates

Vote cast $_{t-1} \times$

signature requirement relative

Vote cast $_{t-1} \times$

signature requirement absolute

Signature requirement relative

Population

Population squared

Per-capita income

Educational attainment

Urbanization

Year effects

State effects

$F$-Statistic $1^{\text {st }}$ stage
(1)

(2)

$9316^{\star \star}$

$13.9^{\star \star \star}$

(5.29)

$-0.401$

(5.93)

$22093^{\text {** }}$

(9074)

0.227

(1.56)

$-0.00008$

(0.0001)

-

$-$

$-$ $8774^{\star \star}$

(4081)

$13.4^{\star \star \star}$

(4.91)

$-0.104$

(5.80)

$22142^{\star \star}$

(9013)

$-0.172$

(1.42)

$-0.00006$

(0.0001)

2.55

(2.07)
(3)

$9408^{\star \star}$

(4369)

$14.1^{\star \star \star}$

(5.39)

$-0.405$

(5.95)

$22115^{\star \star}$

(9079)

0.228

(1.56)

$-0.00008$

(0.0001)

-

110

(718)
(4)

$9812^{\star \star}$

(4688)

$14.4^{\star \star \star}$

(5.49)

$-0.160$

(6.00)

$22183^{\star \star}$

(9167)

0.405

(1.57)

$-0.00009$

(0.0001)

$-$

-

$-153$

(186)

yes

yes

yes

11.91 yes

8.39
(5)

$9343^{\star \star}$

(4468)

$14.0^{\star \star \star}$

(5.23)

0.067

(5.86)

$22245^{\star \star}$

(9090)

$-0.007$

(1.42)

$-0.00007$

(0.0001)

2.42

(2.20)

171

$-123$

(183)

10.51

yes

yes

9.78

Sample includes gubernatorial elections from 1946 to 1976 (410 observations). Standard errors (robust to heteroscedasticity and serial correlation) in parentheses. Educational attainment and urbanization measured in percent. 'Signature requirement relative' is an indicator for states with a signature requirement defined as a percentage of either the number of votes or the number of registered voters in the preceding election. 'Signature requirement absolute' is an indicator for states with an absolute definition of the signature requirement. Instrument for number of candidates is Black $\times V R A$. Significance levels: ${ }^{\star \star \star} 1 \% ;{ }^{\star \star} 5 \% ;{ }^{\star} 10 \%$.

only 410 observations (compared to 429 before). The reason is missing information on signature requirements for some state/year cells as mentioned before. Column (1) reports a baseline specification of our structural equation that accounts for the impact of electoral competition along with the gubernatorial vote cast of the preceding election, split into two separate effects depending on whether the petition requirement is defined relative or absolute, the indicator for states with a relative definition, state population and state population squared. The estimated coefficient of the total number of candidates points to a strong impact of electoral competition on the stringency of petition requirements. Our estimates suggest that an additional candidate in gubernatorial elections triggers an increase in the number of required signatures by more than 9,300. The $F$-statistic measuring the predictive power of the excluded instrument 
in the first-stage regression attains a value of 10.3, somewhat above the rule-of-thumb threshold value of 10 suggested by Staiger and Stock (1997) to avoid the problem of weak instruments. ${ }^{14}$ Recall that we use an instrument with is characterized by very limited variation: Black $\times V R A$ switches only once from zero to one for a subset of states and is constant and equal to zero for all others. Given that our identification strategy is extremely parsimonious in terms of the variation that is added to the system by the inclusion of the instrument, the performance of Black $\times V R A$ in the first-stage regression is remarkable. Note also that using the interaction term as the instrumental variable ensures that the difference-in-difference estimations discussed before are very similar to the actual first-stage regressions of our 2SLS approach.

The results also show that some variation in the signature requirement is explained by participation. As expected, however, participation is systematically related to the number of petitions only in states with a relative definition of ballot access requirements. On average, an increase in participation by 1,000 additional votes (holding population fixed) increases the petition requirement by about 14 signatures in the respective states. Furthermore, we also find that states with a relative definition of ballot access requirements are characterized by significantly higher barriers to the entry of minor-party and independent candidates. Evaluated at the sample mean of Vote cast $_{t-1}$, these states require about 34,700 signatures more than states with an absolute definition. This regularity is confirmed throughout our analysis and stems from the fact that most states with an absolute definition demand around 500 to 10,000 signatures, whereas even moderately populous states with a rule requiring one or two percent of the vote cast in the preceding election tend to have significantly stricter effective requirements.

Columns (2) to (4) each add one of the additional control variables, without substantially affecting the results. The estimated coefficients of the number of candidates range from 8,800 to 9,800 and are all significant at the 5\% level. The coefficients of the remaining control variables are also robust to the changes in specification. Fi-

\footnotetext{
${ }^{14}$ Note that with a single instrument our model is exactly identified and we therefore cannot run formal weak identification tests according to Stock and Yogo (2005).
} 
nally, Column (5) reports an estimation that includes all our control variables. The results almost duplicate the outcome from Column (1). Taken together, the inclusion of additional controls does not seem to have any significant effect on our main result.

\subsection{Robustness}

As discussed above, the instrument used to identify the effect of electoral competition is extremely parsimonious as it captures only variation in electoral competition which comes from the effect of the VRA on states with a strong black minority. There are three southern states, however, which did abolish poll taxes as one important restriction to black voter participation already before 1965/66: South Carolina (1951), Tennessee (1951), and Arkansas (1964). ${ }^{15}$ We therefore suspect that the design of our instrument, Black $\times V R A$, is suboptimal in terms of its predictive power in the first-stage regression. To exploit the variation induced by the abolishment of poll taxes prior to 1966, we construct a second IV from the interaction of an indicator for the existence of poll taxes, Polltax, with an indicator for South Carolina, Tennessee, and Arkansas, Early Abolish. By construction, our second IV accounts only for the variation in electoral competition that enters through the deviation of South Carolina, Tennessee, and Arkansas from the remaining southern states in terms of the timing of the abolishment of voting restrictions.

Table 5 reports the results of a series of 2SLS estimations using both Black $\times V R A$ and Polltax $\times$ Early Abolish as IVs. A quick inspection of the results reveals that the estimates for the effect of electoral competition on the stringency of the states' ballot access laws are now slightly higher, ranging from about 9,000 to 10,100. At the same time, the point estimates are more precise: across all five specifications, the effect is estimated to be different from zero at the $3 \%$ level of significance. Note also that the findings regarding the control variables are virtually identical to those

\footnotetext{
${ }^{15}$ Literacy tests were not abolished prior to the Civil Rights Act of 1965, i.e. all states with this kind of barrier to black voter participation were forced to remove the restriction immediately after the CRA. See also Ogden (1958) and Husted and Kenny (1997).
} 
Table 5: IV estimations using refined instruments

Dep. variable: Signature requirement for minor-party and independent cand.'s in gub. elections

Total number of candidates

Vote cast $_{t-1} \times$

signature requirement relative

Vote cast $_{t-1} \times$

signature requirement absolute

Signature requirement relative

Population

Population squared

Per-capita income

Educational attainment

Urbanization

Year effects

State effects

$F$-Statistic $1^{s t}$ stage

Hansen test ( $p$-value)
(1)

$9567^{\star \star}$

$14.0^{\star \star \star}$

(5.21)

$-0.560$

(6.10)

$22080^{\star \star}$

(9091)

0.237

(1.55)

$-0.00008$

(0.0001)

-

$-$

$-$

yes

yes

6.51

0.82

yes

yes

6.41
(2)

(3)

$9044^{\star \star}$

(3872)

$13.5^{\star \star \star}$

(4.85)

$-0.276$

(5.94)

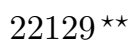

(9022)

$-0.166$

(1.42)

$-0.00006$

(0.0001)

2.58

(2.11)

-
(4)

$9671^{\star \star}$

(4143)

$14.1^{\star \star \star}$

(5.31)

$-0.574$

(6.12)

$22100^{\star \star}$

(9101)

0.239

(1.55)

$-0.00008$

(0.0001)

104

(734)

(4575)

$14.6^{\star \star \star}$

(5.44)

$-0.308$

(6.16)

$22175^{\star \star}$

(9175)

0.424

(1.56)

$-0.0001$

-

(5)

$10090^{\star \star} \quad 9660^{\star \star}$

(4293)

$14.2^{\star \star \star}$

(5.17)

$-0.102$

(6.01)

$22236^{\star \star}$

(9094)

0.011

(1.41)

$-0.00007$

(0.0001) (0.0001)

2.44

(2.25)

170

(736)

$-132$

$-161$

(188)

(184)

yes

yes

yes

yes

yes

5.32

yes

6.80

0.80

5.22

0.82

0.76

Sample includes gubernatorial elections from 1946 to 1976 (410 observations). Standard errors (robust to heteroscedasticity and serial correlation) in parentheses. Educational attainment and urbanization measured in percent. 'Signature requirement relative' is an indicator for states with a signature requirement defined as a percentage of either the number of votes or the number of registered voters in the preceding election. 'Signature requirement absolute' is an indicator for states with an absolute definition of the signature requirement. Instruments for number of candidates are $B l a c k \times V R A$ and Polltax $\times$ Early Abolish. See text for details. Significance levels: ${ }^{\star \star \star ~} 1 \% ;{ }^{\star \star} 5 \% ;{ }^{\star} 10 \%$.

in Table 4. With two IVs for one endogenous explanatory variable, we can now also test the overidentifying restriction. The Table reports $p$-values for the Hansen test, indicating for all specifications that the overidentifying restriction is not rejected at any reasonable level.

To describe the degree of electoral competition, we have so far used the total number of candidates appearing on the ballot. As discussed above, one might argue that the total number of candidates is not a suitable measure for electoral competition in a regression with the stringency of ballot access requirements for minor-party and independent candidates as the dependent variable. Therefore, we repeat all estimations from Table 5 using an alternative measure of electoral competition which excludes all major party 
Table 6: IV estimations, major party candidates excluded from competition measure

Dep. variable: Signature requirement for minor-party and independent cand.'s in gub. elections

(1)

$(2)$

(3)

(4)

(5)

\begin{tabular}{lccccc}
\hline \# of minor-party \& independent cand's & $\begin{array}{c}10229^{\star \star} \\
(4650)\end{array}$ & $\begin{array}{c}9641^{\star \star} \\
(4254)\end{array}$ & $\begin{array}{c}10501^{\star \star} \\
(4821)\end{array}$ & $\begin{array}{c}10801^{\star \star} \\
(5161)\end{array}$ & $\begin{array}{c}10475^{\star \star} \\
(4891)\end{array}$ \\
Vote cast $t-1 \times$ & $14.9^{\star \star}$ & $14.3^{\star \star}$ & $15.2^{\star \star}$ & $15.5^{\star \star}$ & $15.2^{\star \star}$ \\
signature requirement relative & $(6.16)$ & $(5.68)$ & $(6.44)$ & $(6.41)$ & $(6.20)$ \\
Vote cast $_{t-1} \times$ & -0.980 & -0.661 & -1.01 & -0.795 & -0.548 \\
signature requirement absolute & $(6.79)$ & $(6.55)$ & $(6.84)$ & $(6.90)$ & $(6.69)$ \\
Signature requirement relative & $21105^{\star \star}$ & $21214^{\star \star}$ & $21135^{\star \star}$ & $21137^{\star \star}$ & $21274^{\star \star}$ \\
& $(10024)$ & $(9880)$ & $(10007)$ & $(10155)$ & $(9973)$ \\
Population & 0.061 & -0.383 & 0.060 & 0.228 & -0.225 \\
& $(1.67)$ & $(1.51)$ & $(1.65)$ & $(1.67)$ & $(1.50)$ \\
Population squared & -0.00008 & -0.00005 & -0.00008 & -0.00009 & -0.00007 \\
& $(0.0001)$ & $(0.0001)$ & $(0.0001)$ & $(0.0001)$ & $(0.0001)$ \\
Per-capita income & - & 2.92 & - & - & 2.81 \\
& & $(2.28)$ & & & $(2.44)$ \\
Educational attainment & - & - & 286 & - & 347 \\
& & & $(735)$ & & $(726)$ \\
Urbanization & - & - & - & -151 & -129 \\
& & & & $(198)$ & $(194)$ \\
\hline Year effects & yes & yes & yes & yes & yes \\
State effects & yes & yes & yes & yes & yes \\
$F$-Statistic $1^{s t}$ stage & 5.66 & 5.68 & 5.61 & 4.63 & 4.34 \\
Hansen test $(p$-value $)$ & 0.97 & 0.92 & 0.96 & 0.95 & 0.91 \\
\hline
\end{tabular}

Sample includes gubernatorial elections from 1946 to 1976 (410 observations). Standard errors (robust to heteroscedasticity and serial correlation) in parentheses. Educational attainment and urbanization measured in percent. 'Signature requirement relative' is an indicator for states with a signature requirement defined as a percentage of either the number of votes or the number of registered voters in the preceding election. 'Signature requirement absolute' is an indicator for states with an absolute definition of the signature requirement. Instruments for number of candidates are $B l a c k \times V R A$ and Polltax $\times$ Early Abolish. See text for details. Significance levels: ${ }^{\star \star} 5 \%$; ${ }^{\star} 10 \%$.

candidates. As Table 6 indicates, our results are highly robust to this change in the definition of electoral competition. An additional candidate is found to trigger a tightening of the petition requirement by 9,600 to 10,800 signatures. As before, the coefficient of interest remains significant at the $5 \%$ level across all estimations.

So far our identification relies on a single explanatory variable in order to account for the direct effect of participation on the stringency of signature requirements in states with relatively defined ballot access requirements. Of course, the respective coefficient can only capture the average of the changes in the dependent variable that are directly related to changes in participation. One might be worried that this way of controlling for the impact of relative definitions of signature requirements does 
not account for differences in actual regulations within the group of states with such relative rules. To the extent that part of the effective variation in $B$ comes from imperfectly controlled changes in participation, one might still question the validity of the exclusion restriction with respect to our instruments. To cope with this problem, we construct an alternative measure of the petition requirement for states with a relative definition that eliminates all variation that might be driven by participation. This is done by computing the effective number of petitions demanded when a state with a relative definition changes its percent-requirement and keeping this number in all following election years until the state actually changes the underlying rule. Thereafter, the new level is kept until the law is changed again, and so on. With the resulting adjusted series for the signature requirement, participation should lose its explanatory power even for the states where ballot access is defined in relative terms.

As Table 7 reports, the estimations based on the adjusted signature requirements do not alter our results in any significant way. However, the coefficient of interest is now estimated to be somewhat smaller. This might indicate that the previous approach slightly overstated the effect of electoral competition on the stringency of petition requirements. Yet, even with the adjusted signature series, an additional candidate is still estimated to trigger an increase in the barrier of about 7,600 to 9,000 petitions. Our conclusion regarding the strategic behavior of state policymakers when designing of the underlying state rules is thus confirmed. At the same time, the significance of the effect of interest remains at the $5 \%$ level for three out of four specifications. Furthermore, the vote cast in the preceding election is no longer significant. This is in line with our expectations, as the adjustment of the signature series ensures that the variation comes only from real changes in the underlying state regulations and is, therefore, not related to participation.

To summarize, our results reveal that an important institution governing the degree of electoral competition and minority representation in the U.S., namely petition requirements for third-party and independent candidates, is endogenously determined. In fact, the evidence reported here suggests that state policy makers have been actively engaged in re-designing ballot access regulations. The impact of electoral competition 
Table 7: IV estimations using adjusted dependent variable

\begin{tabular}{|c|c|c|c|c|}
\hline \multicolumn{5}{|c|}{ Dependent variable: Adjusted signature requirements in gubernatorial elections } \\
\hline & $(1)$ & $(2)$ & $(3)$ & $(4)$ \\
\hline Total \# of candidates & $\begin{array}{l}7629^{\star \star} \\
(3853)\end{array}$ & $\begin{array}{l}8184^{\star \star} \\
(3924)\end{array}$ & - & - \\
\hline \# of minor-party \& independent cand's & - & - & $\begin{array}{l}8365^{\star} \\
(4465)\end{array}$ & $\begin{array}{l}9037^{\star \star} \\
(4517)\end{array}$ \\
\hline $\begin{array}{l}\text { Vote cast }{ }_{t-1} \times \\
\text { signature requirement relative }\end{array}$ & $\begin{array}{c}5.85 \\
(4.61)\end{array}$ & $\begin{array}{c}6.15 \\
(4.78)\end{array}$ & $\begin{array}{c}6.72 \\
(5.54)\end{array}$ & $\begin{array}{l}7.12 \\
(5.68)\end{array}$ \\
\hline $\begin{array}{l}\text { Vote } \text { cast }_{t-1} \times \\
\text { signature requirement absolute }\end{array}$ & $\begin{array}{l}-2.78 \\
(5.02)\end{array}$ & $\begin{array}{l}-3.08 \\
(5.19)\end{array}$ & $\begin{array}{l}-3.18 \\
(5.44)\end{array}$ & $\begin{array}{l}-3.54 \\
(5.78)\end{array}$ \\
\hline Signature requirement relative & $\begin{array}{c}21774^{\star \star \star} \\
(8039)\end{array}$ & $\begin{array}{c}21759^{\star \star \star} \\
(8035)\end{array}$ & $\begin{array}{c}21004^{\star \star \star} \\
(8642)\end{array}$ & $\begin{array}{c}20924^{\star \star} \\
(8783)\end{array}$ \\
\hline Population & $\begin{array}{l}0.961 \\
(1.28)\end{array}$ & $\begin{array}{l}0.993 \\
(1.28)\end{array}$ & $\begin{array}{l}0.777 \\
(1.32)\end{array}$ & $\begin{array}{l}0.797 \\
(1.33)\end{array}$ \\
\hline Population squared & $\begin{array}{l}-0.00014 \\
(0.00009)\end{array}$ & $\begin{array}{l}-0.00014 \\
(0.00009)\end{array}$ & $\begin{array}{r}-0.00013 \\
(0.0001)\end{array}$ & $\begin{aligned}-0.00014 \\
(0.0001)\end{aligned}$ \\
\hline Per-capita income & $\begin{array}{l}2.32 \\
1.93\end{array}$ & $\begin{array}{l}2.36 \\
(2.01)\end{array}$ & $\begin{array}{l}2.63 \\
2.09\end{array}$ & $\begin{array}{l}2.69 \\
(2.20)\end{array}$ \\
\hline Educational attainment & $\begin{array}{l}374 \\
625\end{array}$ & $\begin{array}{l}372 \\
652\end{array}$ & $\begin{array}{l}515 \\
(624)\end{array}$ & $\begin{array}{c}525 \\
(647)\end{array}$ \\
\hline Urbanization & $\begin{array}{l}-116 \\
181\end{array}$ & $\begin{array}{l}-132 \\
188\end{array}$ & $\begin{array}{c}-117 \\
192\end{array}$ & $\begin{array}{l}-134 \\
(199)\end{array}$ \\
\hline Year effects & yes & yes & yes & yes \\
\hline State effects & yes & yes & yes & yes \\
\hline IV's: $\quad$ Black $\times V R A$ & yes & $\begin{aligned} \text { yes } \\
\text { ves }\end{aligned}$ & yes & $\begin{array}{r}\text { yes } \\
\text { ves }\end{array}$ \\
\hline $\begin{array}{l}\text { Polltax } \times \text { Early Abolish } \\
F \text {-Statistic } 1^{\text {st }} \text { stage }\end{array}$ & $\begin{array}{c}\text { no } \\
9.78\end{array}$ & $\begin{array}{c}\text { yes } \\
5.22\end{array}$ & $\begin{array}{c}\text { no } \\
7.97\end{array}$ & $\begin{array}{c}\text { yes } \\
4.34\end{array}$ \\
\hline Hansen test ( $p$-value) & - & 0.53 & - & 0.68 \\
\hline
\end{tabular}

Sample includes gubernatorial elections from 1946 to 1976 (410 observations). Standard errors (robust to heteroscedasticity and serial correlation) in parentheses. Educational attainment and urbanization measured in percent. 'Signature requirement relative' is an indicator for states with a signature requirement defined as a percentage of either the number of votes or the number of registered voters in the preceding election. 'Signature requirement absolute' is an indicator for states with an absolute definition of the signature requirement. Regarding IVs, see text for details. Significance levels: ${ }^{\star \star} 5 \%$; ${ }^{\star} 10 \%$.

on the design of ballot access rules is strong, and the direction is as expected: the more minor-party and independent candidates appear on the ballot, the more restrictive are, on average, the requirements to get ballot access. Based on the evidence reported here, it appears that the major parties have consistently used their power to frame political institutions in a way that protects their position as incumbents in a setting of duopolistic political competition. 


\section{Conclusion}

This paper starts from the question to what extent political institutions can be regarded as exogenous constraints on political agents. To shed light on this issue, we have examined the design of state ballot access laws in the U.S. from the post-war period to the mid-seventies. Our results suggest that state policymakers have systematically reacted to increased electoral competition by raising the petition requirements that have to be met in order to get access to the ballot in gubernatorial elections. Our findings thus relate to the evidence reported by Trebbi et al. (2007) on the redesign of electoral rules in cities in the U.S. South in reaction to the increased political participation of blacks in the aftermath of the federal Voting Rights Act.

Our identification strategy rests on the idea that the Voting Rights Act has induced variation in electoral competition which is exogenous to the states' ballot access regulations. As a first step of our empirical approach, we have shown that the abolishment of limitations to black voter participation such as poll taxes and literacy tests has indeed significantly raised the number of candidates in gubernatorial elections. We have then provided evidence on the link between electoral competition and the stringency of ballot access restrictions. To overcome the endogeneity problem, we have used instrumental variables which capture the exogenous variation in electoral competition induced by the Voting Rights Act. Across various specifications, the increase in petition requirements triggered by an increase in electoral competition by one additional gubernatorial candidate is estimated to be in the order of 7,600 to 10,800 signatures.

Our results suggest that the endogenous adjustment of state laws governing the access of third-party and independent candidates to general elections has a depressing effect on actual levels of electoral competition. This may have far-reaching consequences, as electoral competition seems to positively affect the quality of governance and economic performance. Besley et al. (2006), for instance, claim that the increase in political competition induced by the Voting Rights Act raised long-run per capita income considerably. Together with their findings, our results suggest that the effort 
of state policymakers to dampen the increase in electoral competition by re-designing the political institutions under their control may have significant welfare costs.

However, a caveat is warranted regarding this interpretation. Lizzeri and Persico (2005), for instance, point to potential drawbacks of electoral competition, arguing that competition induces parties to focus on the interests of a narrower constituency. This in turn may lead to a stronger influence of special interests in politics implying substantial efficiency losses. Under this view the observed adjustment of petition requirements could also be viewed as a socially optimal response to a rising level of electoral competition. In our perspective, however, this rationale for limiting the number of active political parties is unlikely to be valid in the context of the U.S., where the majoritarian voting system already ensures the existence of two dominating political parties. Overall, it is hard to believe that the design of ballot access laws in U.S. states is socially optimal, in particular with regard to the southern states and their pronounced tradition of political marginalization of large groups of voters.

\section{Acknowledgements}

We would like to thank Andreas Haufler, Massimo Bordignon and Michael Bechtel as well as participants of the Congress of the IIPF in Warwick (2007), the Spring Meeting of Young Economists in Lille (2008), and seminars at the University of Munich and the University of Konstanz for useful comments. We also thank Richard Winger for generously sharing with us his knowledge on ballot access laws and the staff of the Max Planck Institute for Comparative Public Law and International Law in Heidelberg for their help and hospitality. Marcus Drometer gratefully acknowledges financial support from the Bavarian Graduate Program in Economics. 


\section{References}

Acemoglu, D., And J. Robinson (2000): "Why did the West extend the franchise: Democracy, inequality and growth in historical perspective," Quarterly Journal of Economics, 115, 1167-1199.

Aghion, P., A. Alesina, and F. Trebbi (2004): "Endogenous political institutions," Quarterly Journal of Economics, 119, 565-611.

Alesina, A., And E. Glaeser (2004): Fighting poverty in the US and Europe: A world of difference. Oxford University Press, Oxford.

Ansolabehere, S., And A. Gerber (1996): "The effects of filling fees and petition requirements on U.S. House elections," Legislative Studies Quarterly, 21, 149-164.

Besley, T., T. Persson, and D. Sturm (2006): "Political competition and economic performance: Theory and evidence from the United States," Mimeo, University of Stockholm.

Botт, A. J. (1990): Handbook of United States election laws and practices. Greenwood Press, Westport.

Drometer, M., And J. Rincke (2008): "The impact of ballot access restrictions on electoral competition: Evidence from a natural experiment," Mimeo, University of Munich.

Duverger, M. (1964): Les partis politiques. Colin, Paris.

Grofman, B. N., R. G. Niemi, and L. Handley (1992): Minority representation and the quest for voting equality. Cambridge University Press.

Husted, T., And L. Kenny (1997): "The effect of the expansion of the voting franchise on the size of government," Journal of Political Economy, 105, 54-82.

ICPSR (1994): Candidate and constituency statistics of elections in the United States, 1788-1990 [computer file]. Ann Arbor, Michigan (Inter-University Consortium for Political and Social Research). 
Lawson, S. F. (1976): Black ballots. Columbia University Press, New York.

Lizzeri, A., And N. Persico (2005): "A drawback of electoral competition," Journal of the European Economic Association, 3, 1318-1348.

Ogden, F. D. (1958): The poll tax in the south. The University of Alabama Press, Tuscalooca.

Persson, T., and G. Tabellini (2003): The economic effects of constitutions. MIT Press, Cambridge.

Rodrik, D. (1999): "Democracies pay higher wages," Quarterly Journal of Economics, 114, 707-739.

Scammon, R. M.: America votes. A handbook of contemporary American election statistics. Congressional Quarterly, Washington (various years).

Staiger, D., And J. H. Stock (1997): "Instrumental variables regression with weak instruments," Econometrica, 65(3), 557-586.

Stock, J. H., And M. Yogo (2005): "Testing for weak instruments in linear IV regression," in Identification and inference for econometric models: Essays in honor of Thomas Rothenberg, ed. by D. W. Andrews, and J. H. Stock, pp. 80-108. Cambridge University Press, Cambridge.

Stratmann, T. (2005): "Ballot access restrictions and candidate entry in elections," European Journal of Political Economy, 21, 59-71.

Trebbi, F., P. Aghion, and A. Alesina (2007): "Electoral rules and minority representation," Mimeo, Harvard University.

United States Bureau of the Census : Statistical abstract of the United States. Washington D.C. (various years).

Winger, R. (2006): "How many parties ought to be on the ballot? An analysis of Nader vs. Keith," Election Law Journal, 5, 170-200. 